\title{
Nitrogenase Synthesis in Klebsiella pneumoniae: Enhanced nif Expression without Accumulation of Guanosine 5'-Diphosphate 3'-Diphosphate
}

\author{
By MRINALINI B. NAIR AND ROBERT R. EADY* \\ AFRC Unit of Nitrogen Fixation, University of Sussex, Brighton BN1 9RQ, UK
}

(Received 22 June 1984; revised 19 July 1984)

\begin{abstract}
Derepression of nitrogen fixation (nif) genes in Klebsiella pneumoniae following transfer from $\mathrm{NH}_{4}^{+}$-sufficiency to $\mathrm{N}$-free medium was preceded by rapid expansion of the guanosine $5^{\prime}$-diphosphate $3^{\prime}$-diphosphate (ppGpp) pool. When derepressed in $\mathrm{N}$-free medium supplemented with glutamine $\left(600 \mu \mathrm{g} \mathrm{m}^{-1}\right)$, expression from the nifH and nif $L$ promoters, determined as $\beta$-galactosidase activity in nif::lac merodiploid strains, was stimulated 7-fold and nitrogenase activity 26-fold; ppGpp did not accumulate, remaining at the levels found in $\mathrm{NH}_{4}^{+}$-repressed populations. The relaxed mutant $K$. pneumoniae rel $A 40$, which accumulates only very low levels of ppGpp, showed partial derepression of nitrogenase activity in the presence of glutamine, thus ppGpp is unlikely to be an effector of nif expression. ATP and GTP levels were elevated under conditions where nif expression was enhanced, consistent with previous data suggesting that maintenance of ATP levels is a prerequisite for the expression of nif genes in $K$. pneumoniae.
\end{abstract}

\section{INTRODUCTION}

Following transfer from growth on $\mathrm{NH}_{4}^{+}$to growth on $\mathrm{N}_{2}$, anaerobic cultures of Klebsiella pneumoniae show the stringent response characteristic of $\mathrm{N}$-starved organisms. Stringent control is well studied in Escherichia coli (Gallant, 1979), in which deprivation of a required amino acid abruptly curtails RNA accumulation, increases the rate of protein turnover and arrests net synthesis of glycolytic intermediates, lipid, phospholipid and peptidoglycan (Cashel, 1975; Gallant \& Lazzarini, 1976). These metabolic changes are accompanied by the accumulation of two nucleotide polyphosphates: guanosine 5'-diphosphate $3^{\prime}$-diphosphate (ppGpp) and guanosine 5'triphosphate $3^{\prime}$-diphosphate (pppGpp) (Cashel \& Gallant, 1969). ppGpp is known to have various regulatory effects central to the stringent response. Apart from its effects on the activities of metabolic enzymes (Gallant, 1979), it also inhibits transcription of stable RNA species (rRNA and tRNA), by affecting the conformation and specificity of RNA polymerase (Travers et al., 1981 ; Travers et al., 1982), and stimulates the transcription of a number of operons, e.g. lac (Gallant \& Lazzarini, 1976), his and trp (Gallant, 1979).

The role of ppGpp as a unique effector molecule has been questioned. A lack of correlation between stringent response and an increase in the intracellular concentration of ppGpp has been reported (Hansen et al., 1975; Donini et al., 1978; Pao \& Gallant, 1979; Pao \& Dyess, 1981; Spadaro et al., 1981; Belitsky \& Kari, 1982). However, this interpretation has been criticized by Ryals et al. $(1982 a, b)$ on the grounds that the methods used to measure RNA synthesis were not rigorous enough.

On starvation for fixed $\mathrm{N}, \mathrm{N}_{2}$-fixing bacteria respond with changes in ppGpp levels (Kleiner \& Philips, 1981), a decrease in the intracellular level of amino acids (Drozd et al., 1972; Ohmori \& Hattori, 1974; Kleiner, 1979; Friga et al., 1981) and the stabilization of mRNA (Kahn et al., $1982 a$ ). Under these conditions the nitrogen fixation genes (nif) are derepressed.

In $K$. pneumoniae, regulation of nif expression by fixed $\mathbf{N}$ is complex, occurring at two levels (for brief reviews see Merrick, 1982; Dixon et al., 1984; de Bruijn et al., 1984). The first involves a centralized $n t r$ system which exerts a general control on nitrogen metabolism and is mediated by the $n \operatorname{tr} A(g \ln F), n \operatorname{tr} B(g \ln L)$ and $n \operatorname{tr} C(g \ln G)$ gene products; the second involves a $n i f$ specific 
regulation by the product of nif $A$ (positive effector) and the product of nif $L$ (negative effector). The nif $L A$ promoter itself is regulated by the $n t r$ system, and is the primary target for regulation of nif expression in response to available fixed $\mathrm{N}$ (Drummond et al., 1983).

Although a model for nif regulation has been developed, the underlying physiological basis is poorly understood. Studies with mutants unable to assimilate added $\mathrm{NH}_{4}^{+}$into glutamine, or inhibition of this process by methionine sulphoximine (MSX), have shown that repression of nif by $\mathrm{NH}_{4}^{+}$requires its assimilation into glutamine (Gordon \& Brill, 1972).

As with various other operons, ppGpp has been implicated in the regulation of nif expression in $K$. pneumoniae for two reasons. Firstly, relaxed mutants unable to synthesize ppGpp do not derepress nitrogenase (Reisenberg et al., 1982). Secondly, in wild-type $K$. pneumoniae as in Clostridium pasteurianum, Azotobacter vinelandii and Rhodopseudomonas palustris, the appearance of nitrogenase activity is preceded by expansion of ppGpp pools, and repression by added $\mathrm{NH}_{4}^{+}$is accompanied by a rapid concomitant decrease in ppGpp levels (Kleiner \& Philips, 1981; Zumft \& Neumann, 1983). However, in $K$. pneumoniae, provision of fixed nitrogen as amino acids does not always repress nif expression (Shanmugam \& Morandi, 1976) and in particular, glutamine has a differential repressive effect on the nifL and nifH promoters (Merrick et al., 1982).

We have investigated the correlation between ppGpp levels and both the extent of transcription of nif $H$ and nif $L$ promoters, and the nitrogenase activity, in $K$. pneumoniae during derepression under both relaxed and stringent conditions, generated by the presence or absence of glutamine in the medium. Our data show that the levels of ppGpp do not correlate with the extent of nif derepression. A preliminary report of some of this work was given by Nair \& Eady (1984). Also our results are consistent with a previous report (Jensen \& Kennedy, 1982) that ATP has a role in the regulation of nif expression.

\section{METHODS}

Organisms and growth conditions. Three $K$. pneumoniae strains were used: the wild-type M5a1, UNF619(pMF183) [nif ${ }^{+} \Delta$ lac/nifH 2783::Mud(Aplac)] and UNF619(pMF182) [nif ${ }^{+} \Delta$ lac/nifL 2782::Mu$\mathrm{d}(\mathrm{Ap} / a c)]$. The $n i f-l a c$ fusion strains are both merodiploids carrying the $l a c Z$ gene (encoding $\beta$-galactosidase) fused in (nif $H$ ), the structural gene for the Fe protein of nitrogenase, or nif $L$, the nif $L$ product being the negative effector of other operons in the nif regulon (Dixon et al., 1980). The relaxed mutant $K$. pneumoniae relA40 was a gift from Dr Casba Kari (Institute of Genetics \& Biochemistry, Szeged, Hungary).

Cultures in low phosphate medium were grown anaerobically sparged with $\mathrm{N}_{2}$ in NFDM (Cannon et al., 1974), modified by replacement of the phosphate buffer with $100 \mathrm{~mm}-\mathrm{MOPS} \mathrm{pH} 7 \cdot 2$, and supplemented with $0.2 \mathrm{~mm}$ $\mathrm{HPO}_{4}^{2-}$ and $1.3 \mathrm{mM}-\mathrm{KCl}$. $\left(\mathrm{NH}_{4}\right)_{2} \mathrm{SO}_{4}(15 \mathrm{mM})$ was added as $\mathrm{N}$ source to repress nif expression. At the end of exponential growth, organisms were harvested by centrifugation.

For derepression of nitrogenase, organisms were resuspended at approx. $200 \mu \mathrm{g}$ protein $\mathrm{ml}^{-1}$ in 30 to $40 \mathrm{ml}$ low phosphate medium, either $\mathrm{N}$-free or containing glutamine $\left(600 \mu \mathrm{g} \mathrm{ml}^{-1}\right)$, and incubated under $\mathrm{N}_{2}$ at $30{ }^{\circ} \mathrm{C}$. These organisms were used as parallel unlabelled cultures for the measurement of nitrogenase activity, ATP levels, $\beta$ galactosidase activity and glutamine uptake as described below.

[ ${ }^{2}$ P]Orthophosphate labelling of nucleotides. In order to equilibrate the nucleotide pools with added isotope before $\mathrm{NH}_{4}^{+}$deprivation, $1 \mathrm{ml}$ of repressed culture was harvested by centrifuging in an Eppendorf centrifuge, resuspended in low phosphate medium containing $15 \mathrm{~mm}-\left(\mathrm{NH}_{4}\right)_{2} \mathrm{SO}_{4}$ and carrier-free [ ${ }^{32} \mathrm{P}$ ] sp. act. $\left.1 \mathrm{Ci} \mathrm{mmol}^{-1}, 200 \mu \mathrm{Ci} \mathrm{m}^{-1}(1 \mathrm{Ci}=37 \mathrm{GBq})\right]$ and shaken for 120 to 150 min under $\mathrm{N}_{2}$. Cultures were then harvested rapidly and resuspended in derepressing medium, with or without glutamine, as described above for the parallel cultures, except that the medium contained ${ }^{32} \mathrm{P}\left(1 \mathrm{Ci} \mathrm{mmol}{ }^{-1}, 200 \mu \mathrm{Ci} \mathrm{m}^{-1}\right)$.

For estimation of ppGpp and other nucleotides, samples $(20 \mu \mathrm{l})$ were removed at intervals both before and after $\mathrm{NH}_{4}^{+}$deprivation and rapidly mixed with an equal volume of $2 \mathrm{M}$ ice-cold formic acid (Chaloner-Larson \& Yamazaki, 1976). Extracts were analysed, either immediately or after storage at $-20^{\circ} \mathrm{C}$ up to $3 \mathrm{~d}$, by thin layer chromatography on polyethyleneimine cellulose plates (Polygram Cel 300, Macherey Nagel, Düren, FRG). The solvent system was $1.5 \mathrm{M}-\mathrm{KH}_{2} \mathrm{PO}_{4}$ for one-dimensional chromatography, and $1.5 \mathrm{M}-\mathrm{LiCl}$ in $2 \mathrm{M}-\mathrm{HCOOH}$ in the first dimension and $1.5 \mathrm{M}-\mathrm{KH}_{2} \mathrm{PO}_{4}(\mathrm{pH} 3.4)$ in the second dimension for two-dimensional chromatography (Gallant et al., 1976).

ppGpp, pppGpp, GTP and ATP were located by autoradiography, identified by co-migration of added authentic carrier nucleotides detected by quenching of fluorescence under UV light, and quantified by scintillation counting.

Enzymic estimation of $A T P$. In addition to the radiochemical method, ATP was also estimated from unlabelled parallel cultures by bioluminescence assay using the firefly luciferin-luciferase system. Culture samples (1 ml) 
were withdrawn at intervals and mixed quickly into an equal volume of $10 \%$ TCA/4 mM-EDTA mixture with vigorous shaking under $\mathrm{N}_{2}$. ATP was measured as described by Lundin et al. (1976).

Glutamine uptake assay. Glutamine uptake was measured by enzymic determination (Lund, 1974) of the residual glutamine in the supernatant after removal of the organisms by centrifugation.

Enzyme assays. Nitrogenase activity was assayed by $\mathrm{C}_{2} \mathrm{H}_{2}$ reduction, as described by Kahn et al. (1982b), and $\beta$ galactosidase activity as described by Dixon et al. (1980).

\section{RESULTS}

To investigate the putative correlation of ppGpp levels with the expression of nif genes, we imposed an abrupt physiological perturbation by $\mathrm{NH}_{4}^{+}$-deprivation. Under these conditions the onset of nif derepression in various strains is more reproducible (Dixon et al., 1980). In addition, as discussed by Gallant (1979), changes in the pool size of low-molecular-weight regulatory metabolites are more readily observed than would be the case in a gradual readjustment of metabolic processes following exhaustion of $\mathrm{NH}_{4}^{+}$in the medium. To allow correlation of ppGpp levels with nif transcription and activity, merodiploid nif: : lac fusions $\left(\mathrm{Nif}^{+}\right)$were used. Repressed suspensions of wild-type M5a 1, a nif $H$ : : lac $Z$ fusion and a nif $L:: l a c Z$ fusion were derepressed in a low phosphate medium following $\mathrm{NH}_{4}^{+}$-deprivation shiftdown as described in Methods.

Our experiments were designed to allow nif expression under both stringent and relaxed conditions. For cultures derepressing under relaxed conditions, glutamine $\left(600 \mu \mathrm{g} \mathrm{ml}^{-1}\right)$ was included in the medium to relieve stringency. Samples of derepressing suspensions of a nif $H:: l a c Z$ fusion strain or a nifL::lacZ fusion strain were removed at intervals for measurement of $\beta$-galactosidase activity and nucleotide levels. Derepression of nitrogenase activity was monitored by removal of gas samples for the analysis of $\mathrm{C}_{2} \mathrm{H}_{2}$ reduction. The derepression kinetics observed are shown in Fig. $1(a, b)$.

Following transfer from $\mathrm{NH}_{4}^{+}$sufficiency to $\mathrm{N}$-free medium (Fig. $1 a$ ) there was a rapid increase in the level of ppGpp, which peaked at $3360 \mathrm{pmol}(\mathrm{mg} \text { protein })^{-1}$ after approximately $45 \mathrm{~min}$ and then decreased to a high plateau level for the duration of the experiment. As previously observed by Dixon et al. (1980), onset of the transcription of nif $H$ preceded the detection of nitrogenase activity by $1 \mathrm{~h}$. Glutamine prevented the increase in ppGpp (Fig. 1b), which remained at the basal level of approximately 100 pmol (mg protein $)^{-1}$ detected in $\mathrm{NH}_{4}^{+}$-grown repressed cultures, but did not repress nif. On the contrary, the onset of nifH transcription and nitrogenase activity occurred 30 to 40 min earlier compared to $\mathrm{N}$-starved cultures. Comparison of Fig. $1(a)$ and $1(b)$ shows that the presence of glutamine resulted in a 7-fold stimulation of nifH transcription and a 26-fold increase in nitrogenase activity. A similar pattern, with a 7-fold increase, was observed for nifL transcription (data not shown). Thus, in the presence of glutamine, where ppGpp did not accumulate, a higher level of nif expression and nitrogenase activity was observed. This was also observed with the relaxed mutant strain $K$. pneumoniae relA40, where the addition of glutamine stimulated nitrogenase activity 30 -fold to give a specific activity of $2 \cdot 2 \mathrm{nmol} \mathrm{C}_{2} \mathrm{H}_{4}$ min $^{-1}$ (mg protein) $)^{-1}$ after $8 \mathrm{~h}$ derepression.

To determine whether the increased rate of transcription of nif genes was due to the stimulation of general protein synthesis, cultures were pulse-labelled with ${ }^{14} \mathrm{C}$-labelled amino acids to measure the rate of protein synthesis at different times of derepression. In the absence of glutamine the rate of protein synthesis declined initially and then remained at a steady level of $70 \%$ of the initial rate. The presence of glutamine resulted in a gradual stimulation of protein synthesis to a plateau level three- to fourfold higher than the rate of $\mathrm{N}$-starved cultures. It is not clear whether the greater stimulation in the rate of nif expression compared with general protein synthesis is a specific effect. The concentration of glutamine in the medium decreased from 600 to $250 \mu \mathrm{g} \mathrm{ml}^{-1}$ in the $3 \mathrm{~h}$ following removal of $\mathrm{NH}_{4}^{+}$, during which time nif derepression had occurred.

The levels of GTP and ATP were measured radiochemically in suspensions in the period following removal of $\mathrm{NH}_{4}^{+}$. The two nucleotides showed a similar pattern: in the absence of glutamine there was a gradual decrease with time (Fig. 2) and in the presence of glutamine there was a gradual increase to a level which, after $3 \mathrm{~h}$, was twice that of $\mathrm{N}$-starved cultures. Measurement 


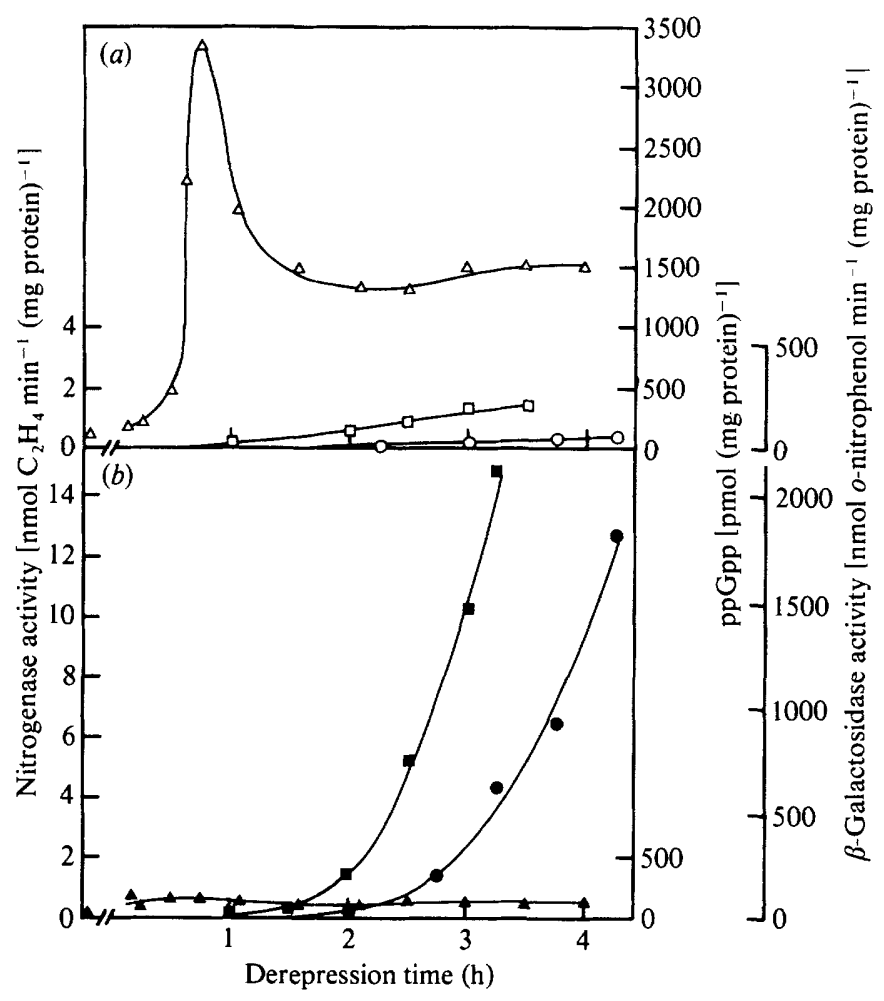

Fig. 1. Kinetics and ppGpp accumulation and nif derepression in $K$. pneumoniae following $\mathrm{NH}_{4}^{+}$shiftdown. A nifH: :lac $Z$ merodiploid strain of $K$. pneumoniae grown in MOPS-NFDM containing $\mathrm{NH}_{4}^{+}$was harvested and subjected to $\mathrm{NH}_{4}^{+}$-shiftdown at the time indicated by the break in the $x$-axis. Organisms were resuspended either in $\mathrm{N}$-free medium (open symbols, $a$ ) or in medium supplemented with glutamine, $600 \mu \mathrm{g} \mathrm{ml}^{-1}$ (filled symbols, $b$ ). Transcription from the nif $H$ promoter was measured as $\beta$-galactosidase activity $(\square, \square)$, and nitrogenase activity from the rate of $\mathrm{C}_{2} \mathrm{H}_{2}$ reduction $(O, O)$. Cultures derepressed under similar conditions were labelled with ${ }^{32} \mathrm{P}$ and used for determination of ppGpp levels $(\triangle, \Delta)$ as described in Methods.

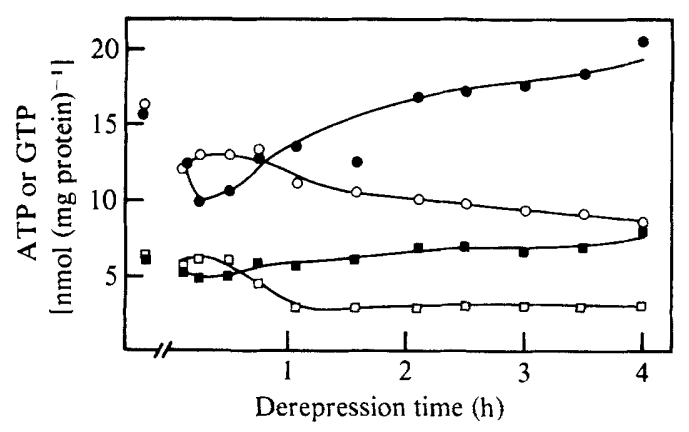

Fig. 2. Effect of glutamine on the levels of ATP and GTP in $K$. pneumoniae following $\mathrm{NH}_{4}^{+}$-shiftdown. ATP $(O, O)$ and GTP $(\square, \square)$ were measured in a nifH::lacZ fusion strain of $K$. pneumoniae derepressed in medium containing ${ }^{32} \mathrm{P}$ in the presence (filled symbols) or absence (open symbols) of glutamine as described in the legend to Fig. 1. 
of ATP levels by the luciferase assay system gave values consistent with those of the radiochemical technique (data not shown).

\section{DISCUSSION}

When nitrogen becomes limiting for growth, free-living $\mathrm{N}_{2}$-fixing bacteria derepress nitrogenase synthesis. In $K$. pneumoniae and $R$. palustris under these conditions ppGpp accumulates and a stringent response is observed (Reisenberg et al., 1982; Zumft \& Neumann, 1983). During growth of $K$. pneumoniae, $A$. vinelandii and $C$. pasteurianum on $\mathrm{N}_{2}$, elevated levels of ppGpp which decrease rapidly when $\mathrm{NH}_{4}^{+}$is added have been reported (Kleiner \& Philips, 1981).

The involvement of the stringent response in nif derepression has been studied in most detail in $K$. pneumoniae. Two mutants with a relaxed phenotype $\left(\mathrm{RelA}^{-}\right)$and unable to accumulate ppGpp, do not derepress nitrogenase activity following exhaustion of a limiting concentration of $\mathrm{NH}_{4}^{+}$in the growth medium (Reisenberg et al., 1982). In one mutant the rate of synthesis of nitrogenase polypeptides showed a fivefold decrease compared with the wild-type strain. Since nitrogenase activity was restored by an $\mathrm{F}^{\prime}$ rel $A^{+}$plasmid from $E$. coli, it is apparent that derepression of nif under $\mathrm{N}$-starved conditions requires a functional relA product, and a positive involvement of $\mathrm{ppGpp}$ in regulating nif expression has been proposed.

However, our data show that in $K$. pneumoniae there is no correlation between the levels of ppGpp and the extent of nif expression when organisms are derepressed in the presence of glutamine. Only low levels of ppGpp are to be expected under such conditions since the stringent response is triggered by the lack of charged tRNAs, a deficiency which would be corrected by the provision of glutamine, which occupies a central position in amino acid metabolism. The increase that we observed in the rate, both of general protein synthesis and of transcription from the nifH and nif $L$ promoters, is consistent with release from amino acid starvation. This stimulation of nif transcription and nitrogenase activity occurs against the low background level of ppGpp found in $\mathrm{NH}_{4}^{+}$-grown cultures, where nif is repressed, and strongly suggests that ppGpp is not directly involved in nif regulation. This proposal finds some support in the finding that the nif promoter consensus sequence found in $K$. pneumoniae (Beynon et al., 1983) is conserved in the nifH promoter of Rhizobium meliloti (Ow et al., 1983; Better et al., 1983), an organism which fails to accumulate ppGpp on $\mathrm{N}$-shiftdown (Belitsky \& Kari, 1982). In view of the high degree of conservation of the promoter sequences, it would be surprising if the expression from these promoters involved interaction of ppGpp with RNA polymerase in $K$. pneumoniae and not $R$. meliloti.

Why then, is the rel $A$ product important in allowing nif expression under $\mathrm{N}$-deficiency? Following the exhaustion or removal of $\mathrm{NH}_{4}^{+}$, organisms are effectively $\mathrm{N}$-starved before nif is derepressed. No net synthesis of protein can occur and nitrogenase synthesis must be at the expense of turnover of $\mathrm{N}$ reserves. ppGpp has a role in protein turnover since it activates proteases involved in these processes (Bridger \& Paranchych, 1979). The inability of relaxed mutants to derepress $n i f$ can be rationalized if protein turnover is regarded as too slow to allow nitrogenase synthesis within the timescale of the experiments. ppGpp levels in these strains are apparently not sufficient to allow protein turnover. The low level of nif expression observed when the $K$. pneumoniae relA40 mutant is derepressed in the presence of aspartate and adenine (Reisenberg $e t$ al., 1982) could, at least partially, be a consequence of an enhanced rate of protein synthesis. Under these conditions, and when adenine was added alone, ATP levels were elevated 10- to 20fold but nif expression required the presence of aspartate. Since the addition of aspartate alone did not result in nif derepression, the restoration of ATP levels, in the absence of a suitable Nsource, is insufficient to allow derepression of nif. Our data indicate that the addition of glutamine alone is effective both in maintaining ATP levels and in stimulating general protein synthesis to a level where nif expression is observed in the relaxed strain.

The enhanced nif expression we observed in the presence of glutamine occurred under conditions where ATP and GTP pools were elevated. Relaxed strains have low ATP levels unless adenine is added (Reisenberg et al., 1982). Since ATP has been implicated as having a role in nif 
expression in $K$. pneumoniae (Jensen \& Kennedy, 1982), it would appear that there is a more significant correlation of nif expression with ATP or related nucleotides than there is with ppGpp.

The provision by the Association of Commonwealth Universities of a scholarship to M.N. is gratefully acknowledged. We thank Professor J. R. Postgate for critical reading of the manuscript and Miss Beryl Scutt for preparation of the typescript.

\section{REFERENCES}

BELITSKy, B. \& KARI, C. (1982). Absence of accumulation of ppGpp during amino acid starvation in Rhizobium meliloti. Journal of Biological Chemistry 257, 677-679.

Better, M., Lewis, B., Corbin, D., Ditta, G. \& HELINSKI, D. R. (1983). Structural relationships among Rhizobium meliloti symbiotic promoters. Cell 35, 479-485.

Beynon, J., Cannon, M., Buchanan-Wollaston, V. \& CANNON, F. (1983). The nif promoters of Klebsiella pneumoniae have a characteristic primary structure. Cell 34, 665-671.

Bridger, W. A. \& Paranchych, W. (1979). Guanosine tetraphosphate: coordinator of metabolic response to nitrogen starvation in bacteria. Trends in Biochemical Sciences 4, 176-179.

De Bruijn, F. J., Sundaresan, V., Szeto, W., OW, D. W. \& Ausubel, F. M. (1984). Regulation of the nitrogen fixation (nif) genes of Klebsiella pneumoniae and Rhizobium meliloti: role of nitrogen regulation (ntr) genes. In Advances in Nitrogen Fixation Research, pp. 627-633. Edited by C. Veeger \& W. E. Newton. The Hague: Nijhoff/Junk; Wageningen: Pudoc.

Cannon, F. C., Dixon, R. A., Postgate, J. R. \& Primrose, S. B. (1974). Chromosomal integration of nitrogen fixing genes in Escherichia coli. Journal of General Microbiology 80, 227-239.

CASHEL, M. (1975). Regulation of bacterial ppGpp and pppGpp. Annual Review of Microbiology 29, 301-318.

Cashel, M. \& Gallant, J. (1969). Two compounds implicated in the function of the RC gene of E. coli. Nature, London 221, 838-841.

Chaloner-Larson, G. \& Yamazaki, H. (1976). Synthesis of guanosine 5'-triphosphate, 3'-diphosphate in a spoT strain of Escherichia coli. Canadian Journal of Biochemistry 54, 935-940.

Dixon, R., EADY, R., EsPIN, G. Hill, S., ICcarino, M., KAHN, D. \& MERRICK, M. (1980). Analysis of regulation of Klebsiella pneumoniae nitrogen fixation (nif) gene cluster with gene fusions. Nature, London 286, 128-132.

Dixon, R. A., Alvarez-morales, A., Clements, J., Drummond, M. \& MERRICK, M. (1984). Transcriptional control of the nif regulon in Klebsiella pneumoniae. In Advances in Nitrogen Fixation Research, pp. 635-642. Edited by C. Veeger \& W. E. Newton. The Hague: Nijhoff/Junk; Wageningen: Pudoc.

Donini, P., Santonastaso, V., Roche, J. \& Cozzone, A. J. (1978). The relationship between guanosine tetraphosphate, polysomes and RNA synthesis in amino acid starved Escherichia coli. Molecular Biology Reports 4, 15-29.
Drozd, J. W., Tubb, R. S. \& Postgate, J. R. (1972). A chemostat study of the effect of fixed nitrogen sources on nitrogen fixation, membranes and free amino acids in Azotobacter chroococcum. Journal of General Microbiology 73, 221-232.

Drummond, M., Clements, J., Merrick, M. \& Dixon, R. (1983). Positive control and autogenous regulation of the nifLA promoter in Klebsiella pneumoniae. Nature, London 301, 302-307.

Friga, G. M., Brobely, G. \& FARKAS, G. L. (1981). Accumulation of guanosine tetraphosphate (ppGpp) under nitrogen starvation in Anacystis nidulans, a cyanobacterium. Archives of Microbiology 129, 341343.

Gallant, J. A. (1979). Stringent control in E. coli. Annual Review of Genetics 13, 393-415.

Gallant, J. A. \& Lazzarini, R. A. (1976). The regulation of ribosomal RNA synthesis and degradation in bacteria. In Protein Synthesis: a Series of Advances, pp. 309-359. Edited by E. McConkey. New York: Dekker.

Gallant, J., Shell, L. \& Bittner, R. (1976). A novel nucleotide implicated in the response of $E$. coli to energy source downshift. Cell 7, 75-84.

GoRDON, J. K. \& BRILL, W. J. (1972). Mutants that produce nitrogenase in the presence of ammonia. Proceedings of the National Academy of Sciences of the United States of America 69, 3501-3503.

Hansen, M. T., Pato, M. L., Molin, S., Fill, N. \& VON MEYENBERG, K. (1975). Simple downshift and resulting lack of correlation between ppGpp pool size and ribonucleic acid accumulation. Journal of Bacteriology 122, 585-591.

Jensen, J. S. \& Kennedy, C. K. (1982). Pleiotropic effect of his gene mutations on nitrogen fixation in Klebsiella pneumoniae. EMBO Journal 1, 197-204.

KaHN, D., Hawkins, M. \& Eady, R. R. (1982a). Metabolic control of Klebsiella pneumoniae mRNA degradation by the availability of fixed nitrogen. Journal of General Microbiology 128, 3011-3018.

KaHN, D., HaWkins, M. \& EADY, R. R. (1982b). Nitrogen fixation in Klebsiella pneumoniae: nitrogenase levels and the effect of added molybdate on the nitrogenase derepressed under molybdenum deprivation. Journal of General Microbiology 128, 779-787.

KLEINER, D. (1979). Regulation of ammonium uptake and metabolism by nitrogen fixing bacteria. III. Clostridium pasteurianum. Archives of Microbiology 120, 263-270.

KLeiner, D. \& PhiLips, S. (1981). Relative levels of guanosine 5'-diphosphate, $3^{\prime}$-diphosphate (ppGpp) in some $\mathrm{N}_{2}$ fixing bacteria during derepression and repression of nitrogenase. Archives of Microbiology 128, 341-342. 
LUND, P. (1974). L-Glutamine: determination with glutaminase and glutamate dehydrogenase. In Methods of Enzymatic Analysis, vol. 4, pp. 17191722. Edited by H. U. Bergmeyer. New York: Academic Press.

Lundin, A., Rickardsson, A. \& Thore, A. (1976). Continuous monitoring of ATP converting reactions by purified firefly luciferase. Analytical Biochemistry 75, 611-620.

MERRICK, M. J. (1982). A new model for nitrogen control. Nature, London 297, 362-363.

Merrick, M., Hill, S., Hennecke, H., HahN, M., Dixon, R. \& KENNEDY, C. (1982). Repressor properties of nifL gene product in Klebsiella pneumoniae. Molecular and General Genetics 185, 75-81.

NAIR, M. B. \& EADY, R. R. (1984). Enhanced level of nif expression in $K$. pneumoniae without accumulation of ppGpp. In Advances in Nitrogen Fixation Research, p. 743. Edited by C. Veeger, \& W. E. Newton. The Hague: Nijhoff/Junk; Wageningen: Pudoc.

OHMORI, M. \& HATTORI, A. (1974). Effect of ammonia on nitrogen fixation by the blue-green alga Anabaena cylindrica. Plant and Cell Physiology 15, 131-142.

Ow, D. W., Sundaresan, V., Rothstein, D. M., Brown, S. E. \& Ausubel, F. M. (1983). Promoters regulated by the $\operatorname{gin} G(n \operatorname{tr} C)$ and nif $A$ gene products share a heptameric consensus sequence in the -15 region. Proceedings of the National Academy of Sciences of the United States of America 80, 25242528.

PAO, C. \& Dyess, B. (1981). Stringent control of RNA synthesis in the absence of guanosine $5^{\prime} \mathrm{di} 3^{\prime} \mathrm{di}-$ phosphate. Journal of Biological Chemistry 256, 22522257.
PaO, C. \& Gallant, J. (1979). A new nucleotide involved in the stringent response in Escherichia coli. Journal of Biological Chemistry 254, 688-692.

ReisenberG, D., ERdei, S., Kondorosi, E. \& Kari, C. (1982). Positive involvement of ppGpp in derepression of nif operon in Klebsiella pneumoniae. Molecular and General Genetics 185, 198-204.

Ryals, J., Little, R. \& Bremer, H. (1982a). Control of RNA synthesis in Escherichia coli after a shift to higher temperature. Journal of Bacteriology 151, 1425-1432.

Ryals, J., LitTle, R. \& Bremer, H. (1982b). Control of rRNA and tRNA synthesis in Escherichia coli by guanosine tetraphosphate. Journal of Bacteriology 151, 1261-1268.

Shanmugam, K. T. \& Morandi, C. (1976). Amino acids as repressors of nitrogenase biosynthesis in Klebsiella pneumoniae. Biochimica et biophysica acta 437, 322-332.

Spadaro, A., Spena, A., Santonastaso, V. \& Donini, P. (1981). Stringency without ppGpp accumulation. Nature, London 291, 256-258.

Travers, A. A., Kari, C. \& Mace, H. A. F. (1981). Transcriptional regulation by bacterial RNA polymerase. Symposia of the Society for General Microbiology 31, 113-130.

Travers, A. A., Lamond, A. I. \& Mace, H. A. F. (1982). ppGpp regulates the binding of two RNA polymerase molecules of the tyrT promoter. Nucleic Acids Research 10, 5043-5057.

Zumft, W. G. \& NeumanN, S. (1983). Changes in guanosine tetraphosphate level during nitrogenase expression in the phototrophic bacterium Rhodopseudomonas palustris. FEBS Letters 154, 121-126. 